\title{
Complicaciones infecciosas severas del territorio maxilofacial: presentación de casos clínicos
}

\section{Severe infectious complications of the maxillofacial territory: clinical cases presentation}

\begin{abstract}
Mauricio Sandoval ${ }^{1 *}$, María
1. Departamento de Cirugía y Traumatología Maxilofacial, Facultad de Odontología, Universidad de Chile, Chile

2. Cirugía Maxilofacial, Servicio de Odontología, Hospital San Juan de Dios, Chile

${ }^{*}$ Correspondencia autor: Mauricio Eduardo Sandoval Tobar | Teléfono: (56-2) 9781841 | Dirección: Sergio Livingstone Pohlhammer 943, Independencia, Santiago | Correo: msandoval@odontologia.uchile.cl, msandoval3278@yahoo.es

Trabajo recibido el 21/04/2017. Aprobado para su publicación el 05/08/2017
\end{abstract}

\section{RESUMEN}

Las infecciones en el territorio maxilofacial, son cuadros frecuentes, de origen polimicrobiano, con manifestaciones clínicas muy variables y que están asociadas a múltiples vías de ingreso de los microorganismos al territorio. Un gran porcentaje de estas infecciones se origina en la cavidad oral, principalmente en lesiones bacterianas que sufren los dientes.

La compleja anatomía de la cabeza y el cuello, permiten que muchas de estas infecciones se diseminen por espacios profundos, llegando a comprometer órganos o regiones anatómicas adyacentes, que pueden llevar a cuadros clínicos de alto riesgo vital.

Los casos clínicos presentados en este artículo corresponden a pacientes tratados en el hospital San Juan de Dios a causa de procesos infecciosos del territorio maxilofacial, por equipos multidisciplinarios.

PALABRAS CLAVE

Infección maxilofacial, Tumor inflamatorio de Pott, Fascitis necrotizante cervical.

Rev. Clin. Periodoncia Implantol. Rehabil. Oral Vol. 10(3); 169-172, 2017.

\section{ABSTRACT}

Infections in the maxillofacial territory are frequent cases of polymicrobial origin, with very variable clinical manifestations and are associated with multiple entering pathways of microorganisms in the territory. A large percentage of these infections originate in the oral cavity, mainly in bacterial lesions that undergo experienced by the teeth.

The complex anatomy of the head and neck allows many of these infections to spread through deep spaces, leading to compromising adjacent organs or anatomical regions, which can lead to high-risk clinical conditions.

The clinical cases presented in this article correspond to patients treated at the San Juan de Dios hospital because of infectious processes of the maxillofacial territory, by multidisciplinary teams.

KEYWORDS

Maxillofacial Infections, Pott's puffy Tumor, Cervical necrotizing fasciitis.

Rev. Clin. Periodoncia Implantol. Rehabil. Oral Vol. 10(3); 169-172, 2017.

\section{INTRODUCCIÓN}

Las infecciones del territorio maxilofacial (ITM), se refieren a infecciones en los espacios potenciales y planos profundos de la región maxilofacial, cuya anatomía es compleja. Las principales causas de las ITM son las infecciones odontogénicas, linfadenitis y secuelas de traumatismos ${ }^{(1)}$.

La mayoría de las infecciones en el territorio maxilofacial responden apropiadamente al tratamiento quirúrgico y antimicrobiano, sin embargo, en algunos casos la diseminación local de la infección puede conducir al compromiso de espacios cervicales profundos, mediastinitis, trombosis del seno cavernoso o compromiso de la vía aérea. La diseminación sistémica de la infección puede conducir a disfunción orgánica, síndrome de respuesta sistémica inflamatoria (SIRS), o sepsis, y está asociada con morbilidad severa y mortalidad. Factores como la inmunosupresión, diabetes mellitus y múltiples comorbilidades pueden incrementar el riesgo de desarrollar infecciones severas o sepsis ${ }^{(2)}$. La progresión y diseminación puede deberse a múltiples factores, incluyendo la inmunocompetencia del individuo, localización anatómica del proceso infeccioso, virulencia de los micro-organismos, patrones de resistencia de los organismos involucrados, así como también las decisiones del manejo terapéutico ${ }^{(3)}$.

Dada la gravedad que pueden alcanzar las ITM, es muy importante conocer las complicaciones y el manejo de estas en etapas incipientes a través de un estudio completo del cuadro clínico, y por sobre todo la monitorización de su evolución en forma directa. Se presentan dos casos de pacientes que cursaron con complicaciones de infecciones severas del territorio maxilofacial, con una manifestación poco común y una localización infrecuente.

\section{Presentación de casos clínicos}

Caso N`1: Paciente de 38 años, con antecedentes de epilepsia en su adolescencia, consultó de urgencia por aumento de volumen frontal, de una semana de evolución asociado a obstrucción nasal y rinorrea (Fig. 1a). Refiere que comenzó como una pústula de crecimiento progresivo localizada en la región frontal y un aumento de volumen periorbitario en forma concomitante. En esa ocasión el médico tratante solicitó estudio por imágenes y pruebas de laboratorio llegando al diagnóstico 
de absceso frontal, el cual fue tratado de manera ambulatoria por elección del paciente con antibióticos del grupo de los betalactamicos (Amoxicilina $1 \mathrm{grs}$. cada $12 \mathrm{hrs}$.). Al momento del ingreso en el servicio de Cirugía Máxilofacial del Hospital San Juan de Dios se presentó con un aumento de volumen blando, en la región frontal derecha de $4 \mathrm{~cm}$ de diámetro, de características inflamatorias, sin fiebre ni alteraciones de parámetros infecciosos. El paciente fue hospitalizado y manejado con terapia antibiótica endovenosa empírica de Ceftriaxona y Clindamicina. Los nuevos exámenes de laboratorio mostraron leucocitos normales y una PCR (proteína C reactiva) aumentada $(17 \mathrm{mg} / \mathrm{L})$. Luego de la evaluación por Otorrinolaringología y Cirugía Maxilofacial, se solicitó una tomografía computarizada (TC) con contraste de cavidades paranasales y se diagnosticó como tumor inflamatorio de Pott (tumoración y edema de la región frontal causada por un absceso subperióstico secundario a una osteomilitis del seno frontal(4) de foco dentario) (Fig.1).

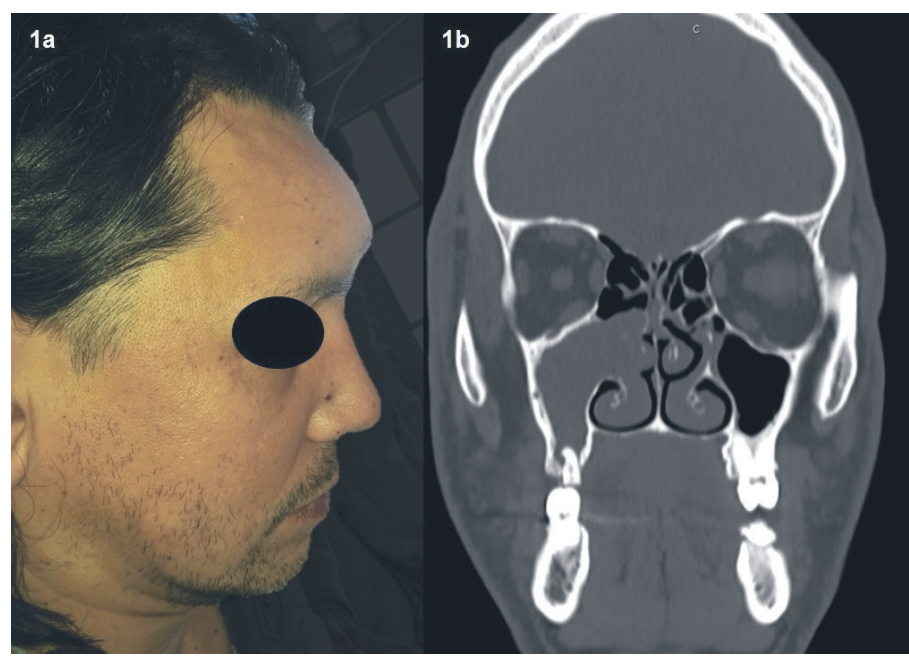

Figura 1: (a) Fotografía Clínica primer día de hospitalización, (b) Imagen de la TC corte frontal, a la altura de diente 1.7

Se realizó una punción aspirativa para drenaje y cultivo bacteriano. Posteriormente se realizó la exodoncia segundo molar superior derecho (diente 1.7) que clínicamente presentaba gran destrucción coronaria y dolor a la percusión vertical. Tras la exodoncia, se observó una comunicación bucosinusal con secreción profusa de contenido purulento desde el seno maxilar. Una semana después del ingreso se realizó el drenaje abierto del seno frontal a través de un colgajo coronal (Fig. 2a), por parte del equipo Otorrinolaringología y Neurocirugía, donde se descarto compromiso de la tabla posterior del seno frontal, y adicionalmente se realizó la desfuncionalización del seno frontal por vía endoscópica nasal.

El paciente fue dado de alta 5 días después con controles ambulatorios por Otorrinolaringología y Cirugía Maxilofacial. Un mes después de la cirugía presenta cierre espontáneo y completo de comunicación bucosinusal, y ausencia de cicatrices o defectos a nivel frontal.

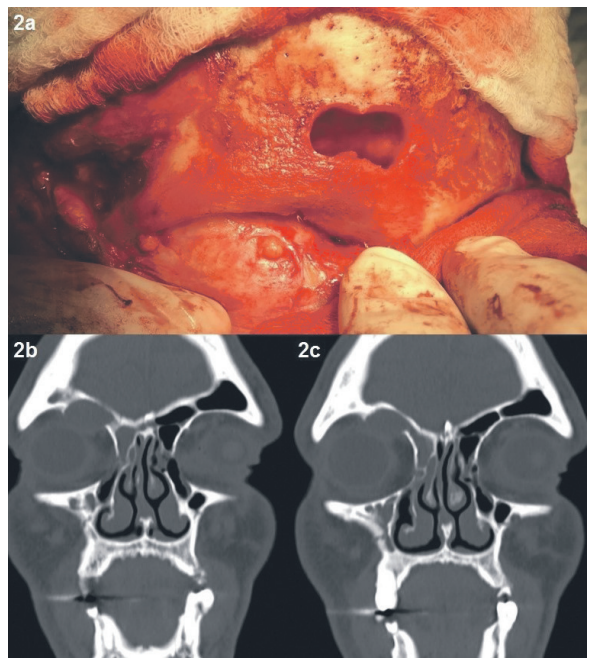

Figura 2: (a) Imagen intraoperatoria vaciamiento quirúrgico del seno frontal, se aprecia ventana ósea patológica de $4 \mathrm{~cm} \times 2 \mathrm{~cm}$ aprox. (b y c) TC Corte frontal, se visualiza compromiso del techo orbitario.
Caso N²: Paciente sexo masculino 71 años con Diabetes Mellitus tipo II insulino requiriente, refiere que sufrió un traumatismo con elemento contundente en región geniana izquierda de un mes de evolución, posterior al golpe cursa con dolor y aumento de volumen en región mandibular izquierda con disfagia y dislalia. Consulta en múltiples servicios de urgencia, siendo tratado con Amoxicilina con Ácido Clavulánico y Analgésicos no esteroidales (Aines), sin una respuesta favorable. Evoluciona con incremento del dolor y aumento de volumen Posteriormente cursa con fiebre y compromiso del estado general y 6 días después consulta al servicio de urgencia del hospital. Al ingreso en el servicio de urgencias, se presenta normotenso y afebril con dolor preauricular punzante progresivo. Al examen físico presenta luxación mandibular izquierda con imposibilidad de cerrar la boca, y desviación severa de la mandíbula a la izquierda asociado a un aumento de volumen parotídeo izquierdo presentando una PCR de 290mg/dl (fig. 3). Al día siguiente es evaluado por Cirugía Maxilofacial, donde se presenta febril, confuso, desorientado y con otorrea izquierda. La evaluación por el servicio de Otorrinolaringología constata presencia de exposición ósea y secreción purulenta en oído izquierdo. Se hospitaliza y se inicia antibioterapia empírica con Ceftriaxona y Metronidazol endovenosa, a su vez se realizaron hemocultivos y cultivo de secreción del conducto auditivo externo (CAE) izquierdo, siendo estos negativos. La TC evidencia fractura de pared anterior del CAE, luxación de articulación témporomandibular (ATM) izquierda y con un proceso inflamatorio extenso en el espacio masticatorio izquierdo (Fig.4). Evoluciona desfavorablemente, con disfagia, requerimientos de oxigenoterapia, aumento de volumen facial y cervical progresivo, elevación de parámetros inflamatorios y coagulopatía. Se modificó la terapia antibiótica a Sulbamox y se tomó una TC con contraste que muestra un aumento de volumen cervical difuso de espacio masticatorio, parafaringeo y bucofaríngeo con abundantes burbujas de aire (Fig.5). Al día siguiente se realizó aseo quirúrgico en pabellón de urgencia de espacios cervicales profundos; intubado con traqueotomía, mediante acceso preauricular, se realizó la exploración de ATM izquierda con extensión cervical e instalación de drenajes. Se realizaron cultivos de las cavidades abscedadas. Posterior al pabellón ingresó a la unidad de cuidados intensivos (UCI), sedado con asistencia ventilatoria mecánica y se continuó el manejo del shock séptico, con apoyo de drogas vasoactivas por al menos $48 \mathrm{hrs}$. Evolucionó con fascitis necrotizante en región cervical anterior y posterior izquierda, sin avanza a mediastinitis; además de una hipertensión arterial concomitante. Se realizaron otros 3 aseos quirúrgicos en pabellón y nuevos cultivos microbiológicos. Luego de 12 días en la $\mathrm{UCl}$ regresa a sala donde presenta una mejoría sostenida y progresiva. Los cultivos mostraron Staphilococus Epidermidis, Cándida y bacilos Gram +, que fueron tratados con antibioterapia endovenosa (Vancomicina, Sulbamox y Fluconazol) hasta completar 6 semanas siendo dado de Alta a los 2 meses desde el ingreso sin signos de infección y parámetro inflamatorios normales (Fig 6 ). Durante este tiempo fue evaluado y tratado por los equipos de cirugía maxilofacial, otorrinolaringología, infectología, medicina y fonoaudilogía.

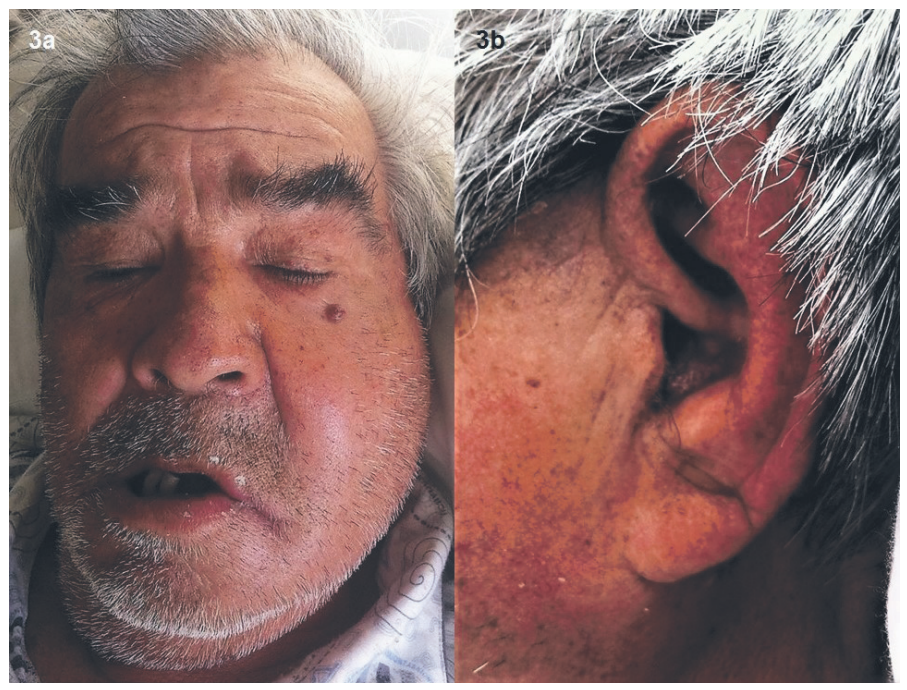

Figura 3: (a) Fotografía clínica frontal: se aprecia aumento de volumen en región parótido-maseterica. (b) Fotografía clínica lateral: se aprecia borramiento del surco pretraqueal debido al aumento de volumen. 


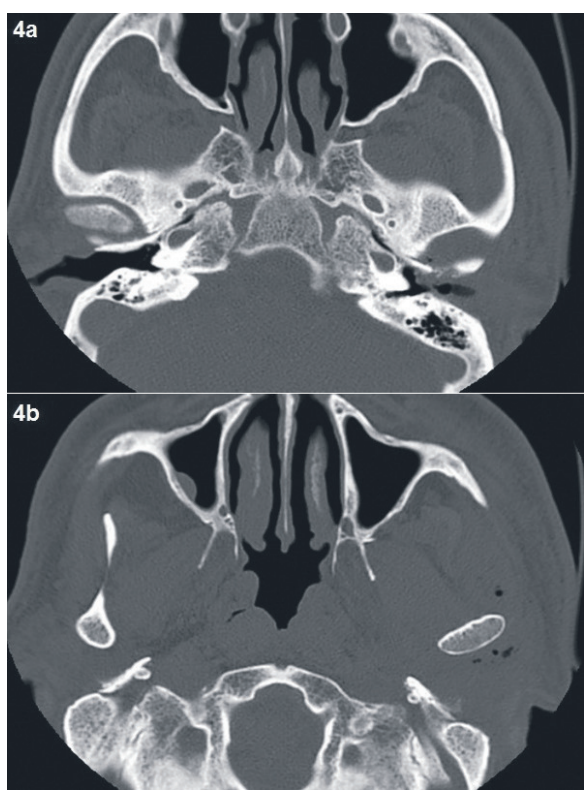

Figura 4: TC corte axial; (a) se observa perforación de la pared anterior del CAE izquierdo, con burbujas aire en su interior; (b) se observa inflamación y burbujas de aire en capsula articula ATM izquierda.

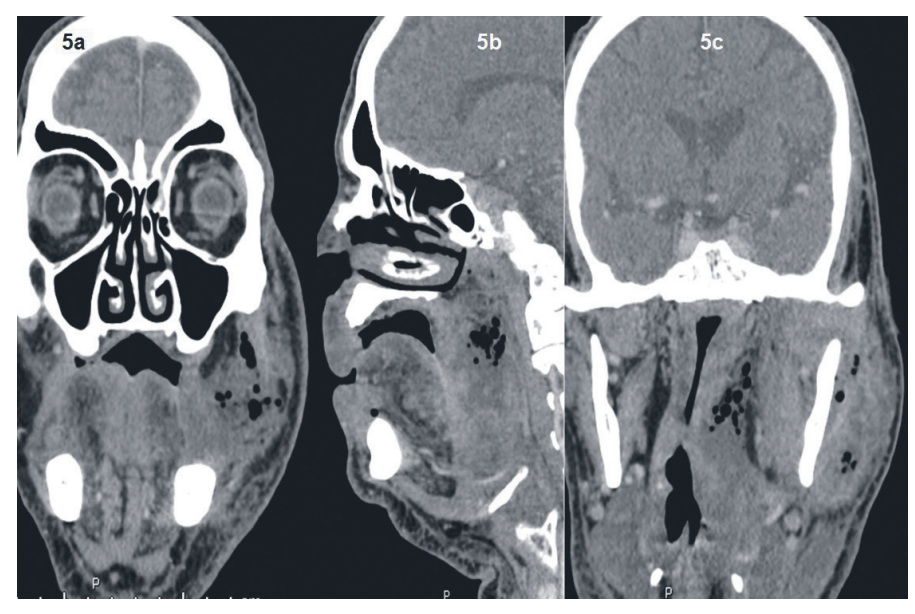

Figura 5: TC con contraste, (a) corte frontal, se aprecia gran aumento de volumen región terigomandibular y espacio masticatorio en general (b) corte parasagital izquiedo, se observa compromiso inflamatorio y burbujas de aire en espacio laterofaringeo; (c) corte frontal a la altura de la vía aérea, se aprecia severo estrechamiento de la vía aérea por compromiso del espacio laterofaringeo.

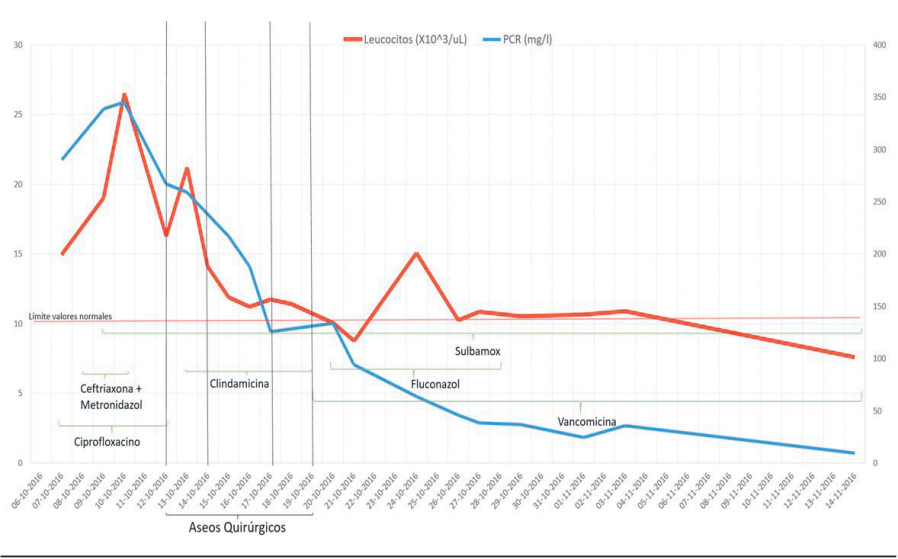

Figura 6: Evolución de la PCR y recuento de leucocitos durante la hospitalización, se destaca su relación con los aseos quirúrgicos y terapias antibióticas implementadas.

\section{DISCUSIÓN}

Las infecciones severas de la cabeza y el cuello, pueden ser de riesgo vital. Un adecuado manejo incluye un diagnóstico oportuno, una intervención quirúrgica y el uso de terapia antimicrobiana apropiada. En ambos casos se puede apreciar una demora en consultar a un centro de salud, donde su evaluación generó un subdiagnóstico, dando lugar a tratamientos antibióticos inefectivos; asociados a una rápida evolución del cuadro infeccioso y del compromiso del estado general.

En el primer caso la diseminación y avance de la infección puede estar asociada a la ausencia de sintomatología en etapas previas, puesto que no se pesquisó en el paciente ningún antecedente de relevancia clínica que pudiera afectar el progreso de la infección. El tumor inflamatorio de Pott es una complicación infecciosa que se considera de alto riesgo ya que presenta a su vez complicaciones intracraneales (meningitis, absceso epidural, empiema subdural, absceso cerebral y trombosis del seno cavernoso), e intraorbitarias (celulitis o abscesos orbitarios) (5); sin embargo en este caso tuvo una evolución favorable sin avanzar a un estado de riesgo vital. Es una patología rara en la época actual, considerando las mejoras en la farmacología de los antibióticos y el acceso universal a fármacos. Solo se han reportado dos casos en nuestro país ${ }^{(6,7)}$

En el segundo caso el mal control metabólico del paciente ${ }^{(8)}$, y la progresión de la infección por los espacios profundos de cuello, junto con los errores diagnósticos en etapas previas, contribuyeron en agravar la severidad de la infección, cursando con una evolución tórpida y desfavorable causándole un shock séptico y una fascitis necrotizante descendente, que lo mantuvo en riesgo vital durante un largo periodo de hospitalización. La fascitis necrotizante de cuello es una infección poco frecuente de los tejidos blandos, de diseminación rápida, polimicrobiana, caracterizada por una necrosis extensa y formación de gas subcutáneo bajo la fascia superficial( ${ }^{(9)}$. Se considera de riesgo vital dado que produce una obstrucción de la vía aérea, y que su progresión, puede llevar a una mediastinitis necrotizante descendente, causando la muerte del paciente por shock séptico, falla multiorgánica o síndrome de distrés respiratorio(10).

Los estudios han demostrado que la diabetes mellitus, infecciones de múltiples espacios faciales, el conteo de leucocítos sobre $15 \times 10^{(9)} \mathrm{u} / \mathrm{L}^{(11)}$, edad sobre 65 años, dificultades respiratorias y temperatura de ingreso sobre $39^{\circ} \mathrm{C}$ se asocian significativamente con complicaciones de riesgo vital $^{(12)}$. Se ha visto que el conteo de leucocitos se asocia con la respuesta al tratamiento y junto con la temperatura del paciente son importantes indicadores de severidad de la infección. Por otra parte se ha visto la concentración sérica de la proteína $C$ reactiva (PCR) como un predictor significativo de los días de hospitalización de estos pacientes, en donde existe una relación lineal directamente proporcional entre la PCR al inicio del tratamiento y los días de hospitalización de un paciente con infección

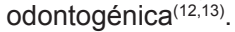

\section{CONCLUSIÓN}

Las infecciones de espacios profundos del territorio maxilofacial son cuadros severos, complejos y potencialmente mortales que deben ser manejados en forma cuidadosa, oportuna y agresiva por un equipo multidisciplinario en un ambiente hospitalario. Sin embargo es aún mas importante realizar un diagnostico completo y oportuno, y una pronta hospitalización cuando se sospecha de compromiso infeccioso de espacios profundos de cara y cuello. Algunos de los signos de sospecha clínicos son: disfagia, disnea, fiebre, dislalia y odinofagia asociado a aumento de volumen de cara y cuello.

\section{RELEVANCIA CLÍNICA}

Este trabajo es de interés puesto que las complicaciones aquí presentadas son infrecuentes, con un alto de riesgo de comprometer la vida del paciente y por lo tanto debe establecerse una sospecha clínica prematura, y realizar todos los exámenes que sea necesario para realizar un diagnóstico completo y un tratamiento adecuado y oportuno. Por lo que el odontólogo debe estar en conocimiento de su existencia para evitar un retraso en el diagnóstico y un tratamiento tardío considerando las complicaciones que esto puede causar, ya que muchas veces estos pacientes van a consultar en primera instancia con el odontólogo.

\section{DECLARACIÓN DE CONFLICTO DE INTERÉS Y FUENTE DE FINANCIAMIENTO}

Los autores refieren que no presentan conflictos de interés No existió ningún tipo de financiamiento. 


\section{Bibliografía}

1. Zhang $C$, Tang $Y$, Zheng M, Yang J, Zhu G, Zhou H, et al. Maxillofacial space infection experience in West China: a retrospective study of 212 cases. Int $\mathrm{J}$ Infect Dis. 2010; 14: e414-7.

2. Byers J, Lowe T, Goodall CA. Acute cervico-facial infection in Scotland 2010 patterns of presentation, patient demographics and recording of systemic involvement. Br J Oral Maxillofac Surg. 2012; 50: 626-30.

3. Kim MK, Chuang SK, August M. Antibiotic Resistance in Severe Orofacia Infections. J Oral Maxillofac Surg. 2016 Nov 9. pii: S0278-2391(16)31097-7.

4. McDermott C, O'Sullivan R, McMahon G. An unusual cause of headache: Pott's puffy tumour. Eur J Emerg Med. 2007 Jun; 14: 170-3.

5. Ketenci I, Unlü Y, Tucer B, Vural A. The Pott's puffy tumor: a dangerous sign for intracranial complications. Eur Arch Otorhinolaryngol. 2011; 268: 1755-63.

6. Castro F, Saez E. Complicaciones craneales de las rinosinusitis en pediatría: tumor de Pott's Puffy (PPT), presentación de un caso clínico. Libro de resúmenes del 50o Congreso SOCHIPE; Octubre 2010. Pucón. SOCHIPE; p. 72

7. Reveco S, Miranda D, Arce R, León J. Reporte de caso de adolescente con tumor inflamatorio de Pott. Libro de resúmenes de las IX Jornadas científicas EDF; 19 y 20 Abril 2013; Pichilemu, Chile. Pichilemu: Sociedad Médica sexta región; 2013. p. 3.
8. Zheng L, Yang C, Kim E, Zhang W, Cai X, Jiang B et al. The clinical features of severe multi-space infections of the head and neck in patients with diabetes mellitus compared to non-diabetic patients. Br J Oral Maxillofac Surg. 2012; 50: 757-61.

9. Fernández M, González P, Mardones M, Bravo R. Complicaciones severas de infecciones odontogénicas. Rev. Med. Clin. Condes. 2014; 25: 529-533

10. Pereira Cl, Sánchez G, Basulto F. Fascitis necrotizante de origen odontogénico. A propósito de un caso. Rev Haban Cienc Méd. 2008; 7:105

11. Velasco I, Soto R. Principios para el tratamiento de infecciones odontogénicas con distintos niveles de complejidad. Rev Chil Cir. 2012; 64: 586-98

12. Han $X$, An J, Zhang $Y$, Gong $X$, He Y. Risk Factors for Life-Threatening Complications of Maxillofacial Space Infection. J Craniofac Surg. 2016; 27: 385-90. 13. Stathopoulos P, Igoumenakis D, Shuttleworth J, Smith W, Ameerally P. Predictive factors of hospital stay in patients with odontogenic maxillofacial infections: the role of C-reactive protein. Br J Oral Maxillofac Surg. 2017;55:367-370 